\title{
Scientific Reasons Behind Women Traditions in India - A Brief Review
}

\author{
Dr Hemalatha P.V. ${ }^{1}$, Sai Nidhi V.V.S.N ${ }^{2}$ \\ ${ }^{1}$ SG Lecturer, D.S. Government Degree college for Women, Ongole, AP. \\ ${ }^{2}$ III B.Tech ECE, RISE Krishna Sai Gandhi Group of Institutions, Ongole, AP.
}

\begin{abstract}
Beauty has varied throughout the world with various cultures and traditions. An ideal beauty is an entity. That is admired if it is perfect and decent for eyes. Beauty is inherent in our tradition. Nothing could have become a tradition or custom without having significance. Our article sums it up quite nicely the customs with the possible scientific reasons and significance they carry with them. In the current challenge we made an attempt to bridge traditions and Science i.e. neuroanatomy for aesthetics of Indian women and their dignity, reverence in world society. Most of the Indian customs and traditions are derived from our ancestors. Traditions and customs were taught at a very young age and followed as part of life. Due to Colonization of India different customs and traditions had to co-exist with each other but they never disturbed our ancient traditions.
\end{abstract}

\section{INTRODUCTION}

Yatra naryastu pujyante ramante tatra Devata,

yatraitaastu na pujyante sarvaastatrafalaah kriyaah !

(Rigveda-5.102).

Means divinity rejoices where woman is respected and where they are not respected, all actions become ineffective. Beginning from the birth to death, all Hindus perform hundreds of ceremonies only with the presence of a women i.e. wife/mother.

India is a land of culture. Indian culture solely concentrates on the protection of women in the society for having a healthy and best social order. In India, Women are extolled as Maata, the Mother of nature or embodiment of universe, Shakti, i.e as pure energy "SHAKTI SWAROOPINI". Even now though Indian society is male venerable in nature, mother also enjoys similar, sometimes higher status than father! Comparing the general position of women in our scriptures with other faith, it is an outstanding status in Hinduism. Women traditions in India were crashed by the centuries of incursion.

We the Indians are proud of our Nationality. Women constitute half of the population in the world so also in India. Indian traditions and culture are known universally. A tradition is a belief or behaviour passed down within a group or society with symbolic meaning or special significance with origins in the past. There are a large number of customs that are followed particularly by women of India. Many people believe that these traditions are just superstitions with no logical or scientific motivations. But you will be astonished to know that many of these rituals truly have some scientific reasoning behind them.

As the scientists dwell deeper into the mysteries of these ancient customs, they found that our customs are precipitous with logic and science. These customs vary from place to place. The rituals followed in India are also aimed at bringing a holistic balance between the body, mind and soul. You will really be surprised to know that our fore-fathers were ahead of their times and knew a lot about the health and mental benefits of many things that we do not know even today. As we know that uninterrupted generation and consumption of electric energy takes place in the human body as preached by Maharshi Vaatsyaayana who described the various power centres in human body .Our ancestors elegantly moulded and gave them us in the form of traditions to follow in the name of religion so that we avail those benefits. We feel pleasure to say that almost every solitary Hindu tradition had a scientific reason with a good health motivation behind it. 


\section{IMPORTANCE OF TILAK/KUMKUM /SINDHUR ON THE FOREHEAD}

Any woman who puts a Tilakam on her forehead anywhere in world appears to owe her roots to Bharatavarsha, i.e, India. Beginning with a cradled child to a grandma, all women wear a Tilak or Vermilion .On the forehead, there is a spot i.e Brow centre between the two eyebrows. It is a major nerve point in human body. The red 'kumkum /Tilak between the eyebrows are believed to retain energy in the human body and control the various levels of absorption. It is prepared by blending turmeric, lime and the metal mercury where Mercury is known for removing stress and strain, lime gives cooling effect and turmeric an antibiotic. Due to kumkum the points on the mid-brow region and Aghnya-chakra are automatically pressed to facilitate the face muscles blood supply.

But it is called as Sindhur by married women who carry a physiological significance, when it is applied on the bride's hair partition to distinguish between married and unmarried. Apart from being the symbol of matrimony for a Hindu woman, sindoor (red vermilion powder) has some great health benefits as well. The mercury cools down the body and makes her feel relaxed. It also triggers a sexual drive among them. So widows and unmarried women are prohibited to wear it. Sindoor should be applied straight up to the pituitary gland where all our feelings will be centred. It is suggested that the red colour symbolises power. According to the elders opine tilakam is not only a beautifying serve for women but also a charm to ward off evil.

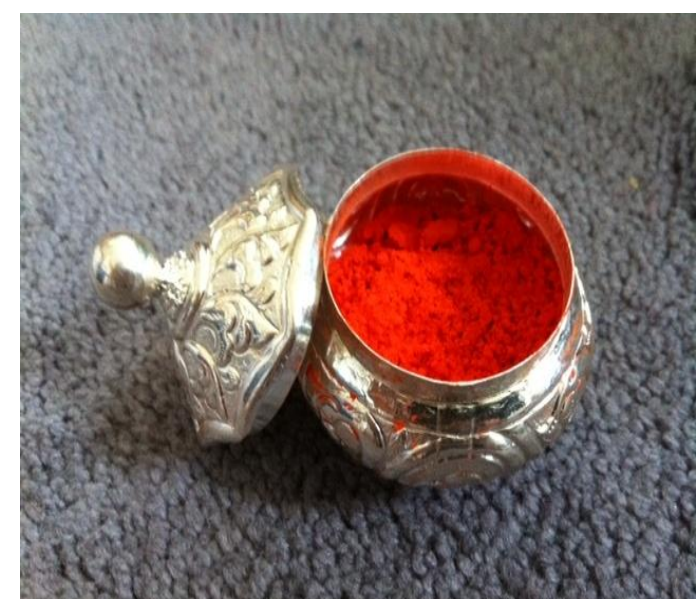

\section{Importance OF Mehendi/Henna On The Hands And FeET}

Henna is not only a great way to decorate and beautify hands and feet but also has many medicinal benefits. It has a cooling effect so when applied it relaxes tense and stressed nerves and prevents nervous breakdown, headaches and other stress related problems common for a women during some times. It is also beneficial for the growth of nails and protects them from viral or fungal infections.

Besides giving beautiful colour to the hands, it is a very powerful medicinal herb also (1). An Indian bride and groom can never be considered complete without mehendi (henna) on their hands and feet because it has strong soothing as well as antiseptic properties. Its cooling effect helps in relieving the couple from stress, headaches and even fever. Application of mehendi can prevent too much stress because it cools the body and keeps the nerves from becoming tense.

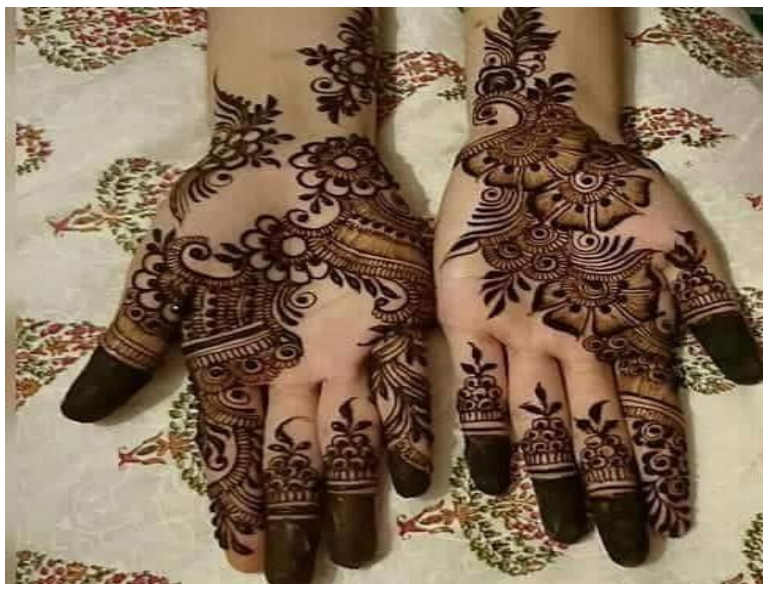




\section{Importance of Ear Piercing}

In Indian ethos, piercing the ears has a great importance. The Indian philosophy says that ear piercing helps in mental power development. Indian physicians and philosophers believe that piercing the ears helps in the growth of intellect, power of thinking and decision making abilities. Particularly the Indian girls have their ears pierced at a very young age as the skin is very delicate and it is less painful. Ear piercing helps in speech-restraint. It helps to reduce impertinent behaviour and the earchannels become free from disorders. This idea appeals to the Western world as well, and so they are getting their ears pierced to wear fancy earrings as a mark of fashion. It increases the calm composure leading to more listening and less speaking and saves our energy.

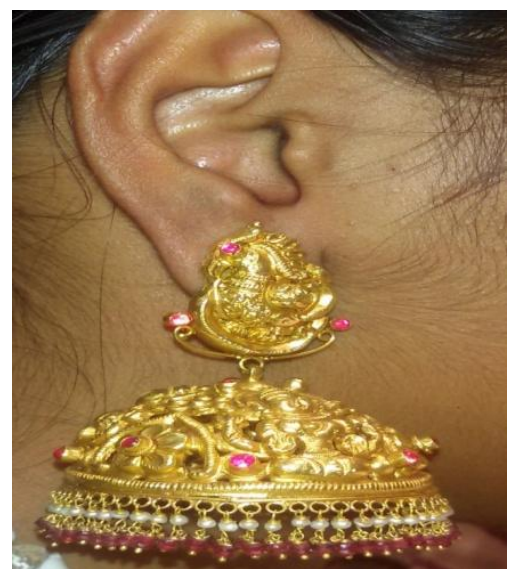

\section{IMPORTANCE OF WEARING BANGLES}

Human body is centre of electric currents and impulses. In India we can see women wearing a bundle of bangles in their both hands. It is a must for married women(2). Normally the wrist portion is in constant activation on any human. The pulse beat in this portion is mostly checked by doctors for all sorts of ailments. The Bangles used are normally in the wrist part of hand. Bangles cause constant friction there which in turn increases the blood circulation level. Furthermore the electricity passing out through outer skin is again reverted to one's own body because of the ring shaped bangles, where round shape has no ends to pass the energy outside but to sends it back to the body.

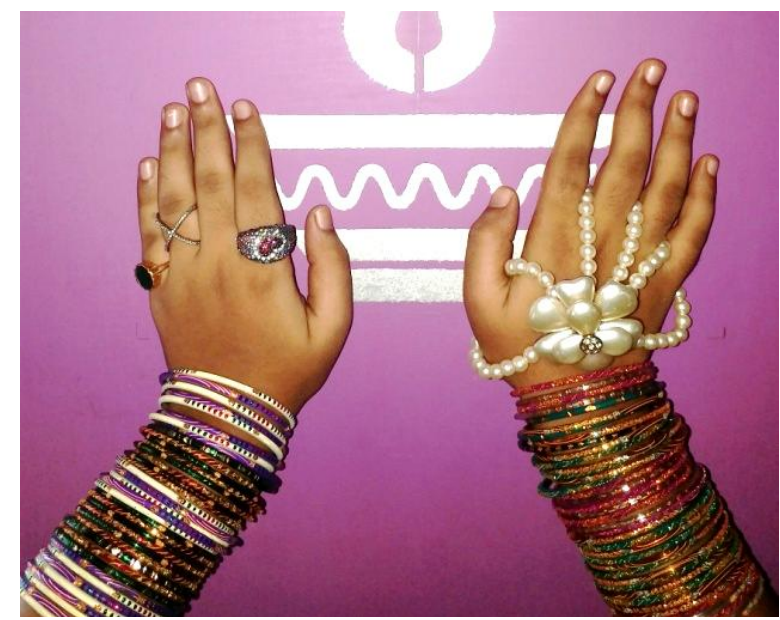

\section{IMPORTANCE OF APPLYING HALDI/TURMERIC}

An Indian woman has a great tradition of applying Haldi on their body parts to bring a natural glow to the body (3). Also there is a tradition of applying a paste of haldi (turmeric) during the ceremony of marriage on the bride and the groom at their respective places before marriage i.e. the Haldi ceremony is to bring brightness on the face of the couple to glow radiantly. The scientific reason behind this custom is that the turmeric is a 'wonder herb' on external application the entire body will receive the best medicinal advantages of turmeric because of its various medicinal properties like antibacterial, antifungal etc. Another traditional reason behind this custom is to fend off evil spirits that cause any harm to the couple. The paste is usually prepared by mixing turmeric with oil to have a moisturising effect on the skin. 


\section{IMPORTANCE OF GROWING LONG HAIR ON HEAD}

Hair is an extension of the nervous system; it can be correctly seen as exteriorized nerves, a type of highly evolved 'feelers' or 'antennae' that transmit vast amounts of important information to the brain stem, the limbic system, and the neocortex. The most sensitive spot is the centre of the head. The tying buns help in preserving the energy and boost this centre. So our grandmothers and mothers are used to wear this hairstyle most of the time.

Even in Ayurveda, Sushrut rishi, the foremost surgeon describes the master sensitive spot on the head as Adhipati Marma, where there is a nexus of all nerves. This can be protected by shikha. The Brahmarandhra, the centre of wisdom occurs below in the brain, where the sushumnã (nerve) arrives from the lower part of the body. The knotted shikhã or choti helps in boosting this centre and conserve its subtle energy known as ojas.

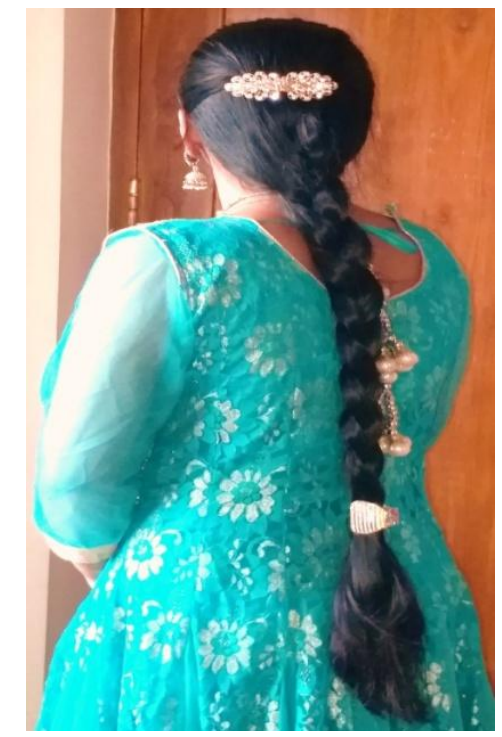

\section{IMPORTANCE OF WEARING ANKLETS \& TOE RingS}

Anklets are worn around ankle, which are called 'Payal' in Hindi, mostly made of silver. This is one of the favourite ornaments of a woman in India which makes a very tuneful sound while walking. This beautiful jewellery regulates blood circulation and thus helps in curing the inflammation of foot soles. It activates lymph glands in the body and boosts immunity. Silver being a conductor of energy, work as a mediator between the earth and human body and makes a woman more energetic while sending the negative energy to earth through foot.

Toe ring or Bichiya is the mandatory traditional Indian ornament which worn by only married woman, in the second toe of both the foot (4). It is not just the significance of married women but there are amazing scientific reasons behind it. As we know Silver is a good conductor, it absorbs polar energies from the earth and passes it to the body to the second toe. It has the nerve connected to the uterus and passes to the heart; hence, wearing ring on this toe strengthens the uterus and regulates the blood flow and the menstrual cycle. So these toe rings makes her menstrual cycle regular and helps in conceiving process to change a girl into a pious mother.

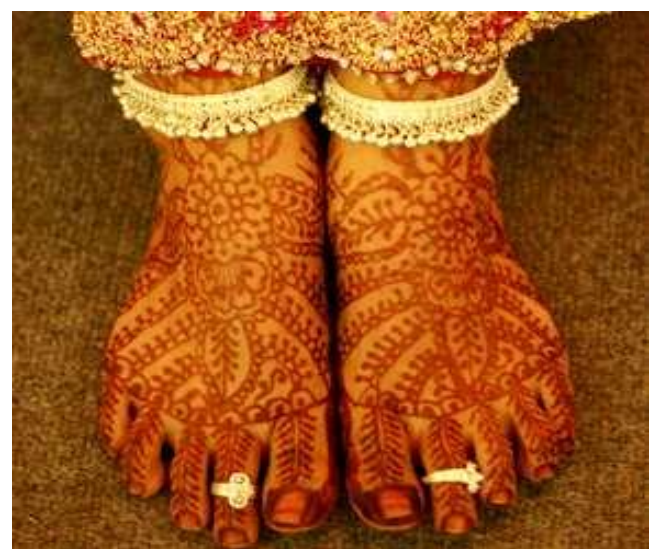




\section{IMPORTANCE OF WEARING MANGALA SUTRA}

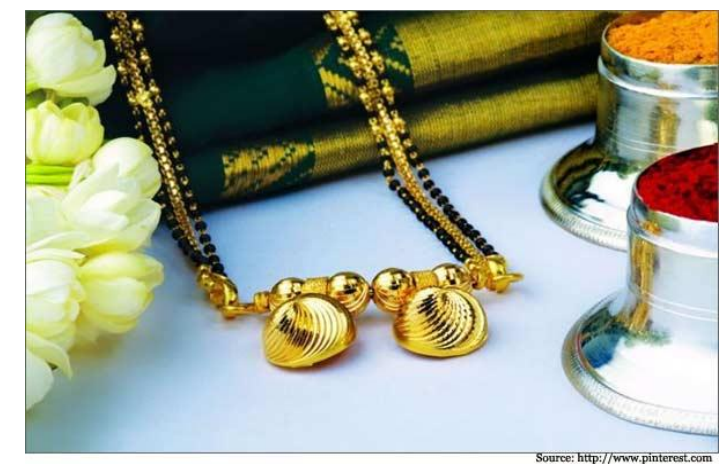

The word Mangalsutra is derived from two words 'Mangal' which means auspicious and 'Sutra' which means thread. Mangalsutra is a pious thread tied by a groom to his bride on the day of marriage which is expected to be worn until her husband's death (5). This binds a woman forever with her husband. It is basically made of gold or turmeric which is known to have healthy effects and on breathing the air around it helps us to develop immune system. Gold has ayurvedic properties like improving heartbeat, helps in the improvement of healthy breast and regularize blood circulation. The Mangalsutra is worn with the hollow side facing the body so that the positive energies are attracted towards the void of the cups. As it is always be hidden, there will be constant friction of the metal gold touching the body portion directly, so the effect will be more to gain the said benefits. This helps to keep the body and mind healthy. As Indian women tend to work hard it also controls the body pressure levels. It is not only an ornament and symbol of being married, but it is a device which empowers Hindu married women to keep their family hale and healthy

\section{Conclusion}

We are thrilled and feel happy to know the real intention of the customs followed in our day to day lives. We have listed a few Indian Customs/Traditions along with the possible scientific reason which we got convinced with. All the reasons used in this article are solely our understanding with some reference; some are from my parents and grandparents. We conclude with an intention that our ancient customs or traditions have grandeur of living. So it is our responsibility to pass on this inheritance of traditions to our future generations for a blissful life. In our analysis, traditions ought to be followed to establish the legitimacy of a particular set of values.

\section{REFERENCES}

[1] “ Antimicrobial Efficacy of Henna Extracts” Kathem K. Al-Rubiay,1 Nawres N Jaber,2 AlMhaawe BH,3 Laith K. Alrubaiy 4 1Department of Dermatology, Basra General Hospital; 2 Department of Microbiology, University of Basra; 3 Department of Pathology, University of Basra; 4 Department of Medicine, Bangor Hospital, UK. Oman Medical Journal 2008, Volume 23, Issue 4, October 2008

[2] "Why women wear Bangles? Here are 5 scientific reasons behind this", All India Roundup, News portal, Chaitu, 14 May, 2017.

[3] “Amazing scientific reasons behind Hindu Wedding traditions" www.youblisher.com/p/ 1410402.

[4] "Scientific reasons behind Indian Traditions", Indian customs, 15th November 2011.

[5] "Why Hindu Women Wear Mangalsutra", By: Sanchita Chowdhury, November 13, 2013, www.boldsky.com > Yoga Spirituality > Faith Mysticism 